\title{
SELF-POWERED THERMOACOUSTIC SENSORS FOR NUCLEAR REACTORS
}

\author{
S. L. Garrett \\ Graduate Program in Acoustics, Penn State, 201 G Applied Science Bldg. University Park, PA 16802. \\ *Corresponding author's e-mail: sxg185@psu.edu
}

Keywords: Standing-Wave Engines, Thermoacoustics, Temperature Measurement, Nuclear Reactor Flux Measurement, Fission Heating, Streaming

\section{Introduction}

The core of a nuclear reactor is a particularly harsh environment when functioning properly. When there is a stress event that may include the loss of electrical service, similar to the earthquake and tsunami that struck the Fukushimi Daiichi reactors on 11 March 2011, the need for robust and reliable self-powered sensors becomes acute. The development and testing of very simple standing-wave thermoacoustic engines that can be configured within nuclear fuel rods to exploit the flux of energetic particles (either neutrons or gamma radiation) will be described [U.S. Pat. Appl. No. 2014/0050293 (Feb. 20, 2014)]. The vibrations of such thermoacoustic engines can produce sound that couples to the surrounding heat-transfer fluid to telemeter the information (as frequency and amplitude) to the exterior of the reactor vessel, without requiring electrical power. The resonance frequency is related to the temperature of the heat transfer fluid that surrounds the thermoacoustic resonator [IEEE Instrumentation and Measurement 16(3), 18-25 (2013)] and the amplitude is proportional to the heating, therefore to the neutron or gamma flux [U.S. Patent Application No. 284117-00634 (J1731857-2), 18 April 2013]. Thermoacoustic resonances are maintained without use of a cold heat exchanger, making the engine quite simple. Removal of waste heat from the ambient-temperature end of the stack is enhanced by nonlinear acoustically-induced streaming. The nonlinear hydrodynamic heat transport limits the temperature of the fissionable material or gammaabsorber that provides the heat that drives the engine. This thermoacoustic technique for selfpowered "wireless" sensing may be applicable to other processes that generate substantial temperature gradients, such as industrial crucibles for melting glasses and metals.

\section{Acknowledgements}

This research is supported by Westinghouse and by Idaho National Laboratory. The author appreciates the services provided by Iain Wilson, Larry Bodendorf, and Brandon Rieck, all of IST Mirion in Cambridge, Ontario, for fabrication of major thermoacoustic resonator parts suitable for service in the core a nuclear reactors. 